\title{
Identifikasi Kandungan Parasetamol Pada Jamu Pegal Linu di Kawasan Pasar Malam Kota Banjarmasin Kalimantan Selatan
}

\author{
Rahmadani $^{1 *}$, Tuti Alawiyah ${ }^{1}$ \\ ${ }^{1}$ Program Studi Sarjana Farmasi, Universitas Sari Mulia, Banjarmasin, Indonesia \\ * corresponding author \\ Email: dani27pharmacy@gmail.com
}

Diterima : 12 Agustus 2021

Direvisi : 23 September 2021
Publikasi : 20 Oktober 2021

doi:10.52216/jfsi.vol4no2p26-30

\begin{abstract}
Herbal products are very well known by the people of Indonesian since ancient times in an effort to prevent disease, treat and restore fitness. Medicinal Chemicals (MCs) are often added to herbal preparations to increase the efficacy of herbal medicine and provide a more instant herbal effect. With an uncertain dose will cause very serious side effects for health. This research was conducted with 5 samples of herbal aches and pains in the night market area of Banjarmasin. The test was carried out by qualitative analysis using Thin Layer Chromatography (TLC) and quantitative analysis using UV-Vis Spectrophotometer. The results of the qualitative test showed the presence of paracetamol BKO in sample $C$ and sample $D$ and the results of the quantitative test resulted in sample $C$ of $8.13 \mathrm{mg} / \mathrm{Kg}$ and sample D of $6.28 \mathrm{mg} / \mathrm{Kg}$.
\end{abstract}

Keywords: Medicinal chemicals, Herb, TLC, UV-Vis Spectrophotometer.

\section{Intisari}

Sediaan jamu sangat dikenal oleh masyarakat Indonesia sudah dimulai sejak zaman dahulu dalam upaya pencegahan penyakit, pengobatan serta mengembalikan kebugaran. Bahan Kimia Obat (BKO) sering ditambahkan ke dalam sediaan jamu untuk menambah khasiat jamu dan memberikan efek jamu yang lebih instan. Dengan dosis yang tidak pasti akan menimbulkan efek samping yang sangat serius bagi kesehatan. Penelitian ini dilakukan dengan 5 sampel jamu pegal linu di kawasan pasar malam kota Banjarmasin. Pengujian dilakukan secara analisis kualitatif menggunakan Kromatografi Lapis Tipis (KLT) dan uji analisis kuantitatif menggunakan Spektrofotometer UV-Vis. Hasil uji secara kualitatif menunjukkan keberadaan BKO parasetamol pada sampel $C$ dan sampel $D$ dan hasil uji secara kuantitatif menghasilkan pada sampel C sebesar $8 ., 13 \mathrm{mg} / \mathrm{Kg}$ dan sampel D sebesar $6,28 \mathrm{mg} / \mathrm{Kg}$.

Kata kunci: Bahan kimia obat, Jamu, KLT, Spektrofotometer UV-Vis.

\section{Pendahuluan}

Penggunaan obat dari bahan alam khususnya yang dikenal dengan "jamu" oleh masyarakat Indonesia sudah dimulai sejak zaman dahulu, terutama dalam upaya pencegahan penyakit, peningkatan daya tahan tubuh, pengobatan serta mengembalikan kebugaran pada tubuh pasca melahirkan atau bekerja keras, bahkan untuk kecantikan dan keintiman wanita (Paryono \& Kuniarum., 2014.)

Akan menjadi suatu masalah apabila penambahan Bahan Kimia Obat (BKO) ke dalam jamu dengan tujuan menambah khasiat jamu dan memberikan efek jamu yang lebih instan dibandingkan jamu yang tidak mengandung BKO. 
Akibat penggunaan jamu yang mengandung BKO dengan dosis yang tidak pasti akan menimbulkan efek samping dari mual, diare, pusing, gangguan penglihatan, nyeri dada sampai kerusakan pada organ dalam tubuh seperti hati, gagal ginjal, jantung bahkan menyebabkan kematian (BPOM, 2011)

Berdasarkan informasi dari World Health Organization (WHO) dan U.S. Food and Drug Administration (FDA) sebanyak 30 obat tradisional dan suplemen kesehatan yang mengandung BKO serta bahan-bahan yang dilarang juga ditemukan di negara-negara ASEAN, Amerika dan Australia (BPOM, 2015). Dan berdasarkan peringatan BPOM pada 11 Desember 2016 terkait obat tradisional yang mengandung $\mathrm{BKO}$ dilarang penggunaannya. Sebanyak 39 obat tradisional mengandung BKO yang 28 di antaranya merupakan obat tradisional yang tidak terdaftar di Badan POM dan 11 lainnya memiliki izin edarnya dibatalkan. Temuan obat tradisional yang teridentifikasi mengandung BKO pada tahun 2016 didominasi oleh jamu pegal linu (penghilang rasa sakit) dan antirematik (BPOM, 2006)

Berdasarkan penelitian terdahulu yang dilakukan oleh Harimurti tahun 2020 menyimpulkan bahwa terdapat 3 sampel jamu yang mengandung Parasetamol dari 14 sampel yang dikumpulkan masing-masing memiliki kadar $0,04 \%$ (b/v), 0,30\% (b/v) dan 0,13\% (b/v). Hal ini menunjukkan bahwa di sediaan jamu yang dikonsumsi masih terdapat $\mathrm{BKO}$ yang dilarang oleh pemerintah. Penelitian yang dilakukan oleh (Tjahjani \& Nasution, 2020) menyimpulkan bahwa terdapat 2 sampel jamu pegal linu yang memiliki tanda registrasi dari Badan POM positif mengandung BKO Parasetamol, hal ini menunjukkan adanya keberadaan BKO pada produk jamu meskipun sudah memiliki tanda registrasi dari Badan POM.

Berdasarkan penelitian sebelumnya peneliti tertarik untuk melakukan penelitian yang serupa dengan metode dan tempat penelitian yang berbeda. Penelitian ini dilakukan di kawasan pasar malam kota Banjarmasin yang terdapat warung jamu di pinggir jalan. Dengan menggunakan instrumen Kromatografi Lapis Tipis (KLT) dan Spektrofotometer UV-Vis untuk melakukan identifikasi terhadap BKO pada sediaan jamu yang tidak memiliki tanda registrasi dari Badan POM. Penambahan BKO diduga adalah obat paracetamol karena berdasarkan hasil penyelidikan dengan wawancara beberapa warga setempat bahwa membeli jamu dengan tujuan pengobatan untuk pusing dan pegal.

\section{Metode Penelitian}

\subsection{Alat dan bahan}

Alat yang digunakan dalam penelitian ini adalah tabung reaksi Pyrex, gelas ukur Pyrex (5 $\mathrm{ml}, 10 \mathrm{ml}$, dan $100 \mathrm{ml}$ ), kertas saring, batang pengaduk, Erlenmeyer Pyrex $100 \mathrm{ml}$, pipet volume Pyrex, timbangan analitik KERN, penangas air, cawan penguap dan Spektrofotometer UV-Vis Shimadzu.

Bahan yang digunakan dalam penelitian ini adalah produk jamu pegal linu yang tidak memiliki tanda registrasi dari Badan POM, serbuk Paracetamol pro analyst, etanol EMSURE absolute for analysis, kloroform EMSURE, methanol EMSURE, Silika GF 254, ammonia, dan etil asetat.

\subsection{Pembuatan Larutan Uji}

Sampel pegal linu ditimbang sebanyak \pm 500 mg. Dimasukkan ke dalam erlenmeyer, ditambahkan $10 \mathrm{ml}$ etanol dikocok selama 30 menit kemudian disaring lalu sari diuapkan di atas penangas air sampai kering. Sisa penguapan dilarutkan dalam $5 \mathrm{ml}$ etanol

\subsubsection{Pembuatan Baku Pembanding PCT}

$0,1 \% \mathrm{~b} / \mathrm{v}$ dalam etanol, baku pembanding PCT ditimbang $100 \mathrm{mg}$, dimasukkan ke dalam labu ukur dilarutkan dengan etanol hingga 100,0 $\mathrm{ml}$ etanol lalu dihomogenkan

\subsubsection{Pembuatan Eluen}

$4,5 \mathrm{ml}$ etil asetat, $5 \mathrm{ml}$ etanol dan $25 \mathrm{ml}$ ammonia dicampur kemudian dimasukkan ke dalam chamber untuk dijenuhkan

\subsubsection{Persiapan Fase Diam}

Plat KLT diaktifkan dengan cara pemanasan pada oven selama 30 menit pada suhu $120^{\circ} \mathrm{C}$, kemudian diberi garis dengan pensil dengan jarak $0,5 \mathrm{~cm}$ dari tepi atas dan $1 \mathrm{~cm}$ dari tepi bawah. Skala masing-masing untuk tempat totolan larutan uji adalah $1,5 \mathrm{~cm}$ 


\subsubsection{Pengerjaan KLT}

Dengan fase diam Silika GF 254 dan fase gerak adalah Etil asetat : Etanol : Ammonia yang dilakukan penjenuhan dengan kertas saring ditotolkan dengan volume $15 \mu \mathrm{L}$ dan jarak rambat $8 \mathrm{~cm}$, lalu dengan penampak bercak pada sinar UV $254 \mathrm{~nm}$.

\subsection{Analisis Kuantitatif Parasetamol dengan} Spektrofotometri UV-Vis.

\subsubsection{Pembuatan Larutan Baku Induk}

Parasetamol ditimbang seksama $100 \mathrm{mg}$, dilarutkan dalam etanol hingga volume tepat 100 $\mathrm{mL}$ (1000 ppm).

\subsubsection{Pembuatan Larutan Baku 100 ppm}

Larutan baku parasetamol diambil $10 \mathrm{~mL}$ kemudian dilarutkan dalam etanol hingga volume tepat $100 \mathrm{~mL}$ (100 ppm).

\subsubsection{Pembuatan Larutan Baku Seri}

Larutan baku seri dibuat dengan konsentrasi 2, 4, 6, 8 dan 10 ppm dengan cara mengencerkan dari larutan baku induk parasetamol $100 \mathrm{ppm}$.

\subsubsection{Pembuatan Larutan Uji Sampel Jamu}

Sampel jamu pegal linu ditimbang sebanyak $\pm 500 \mathrm{mg}$. Dimasukkan ke dalam erlenmeyer, ditambahkan $10 \mathrm{~mL}$ etanol, dikocok selama 30 menit kemudian disaring. Sampel uji dilakukan degasifikasi sebelum diuji ke dalam alat Spektrofotometer UV-Vis

\section{Hasil dan Pembahasan}

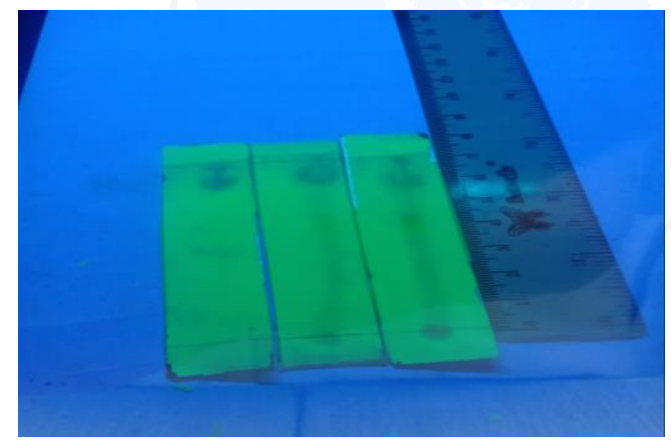

Gambar 1. Hasil analisis kualitatif bercak standar dan sampel jamu pegal linu

Hasil uji kualitatif sampel dan standar parasetamol menggunakan kromatografi lapis tipis (KLT) didapatkan nilai $\mathrm{Rf}$ sebesar 0,75 untuk baku pembanding dengan panjang gelombang UV $254 \mathrm{~nm}$.

Dengan menggunakan fase diam silika GF 254 dan fase gerak yang terdiri dari campuran etil asetat:etanol:ammonia (85:10:5). Pemilihan fase diam silika gel GF 254 digunakan dalam mempermudah tahap identifikasi, yang dimana paparan sinar dengan UV 254 akan berfluoresen sedangkan bercak parasetamol akan teredam sampai bercaknya jelas. Peredaman fuoresensi fase diam disebabkan adanya gugus kromofor dan auksokrom dalam parasetamol yang mampu menyerap sinar UV (Harimurti et al., 2020). Dan berdasarkan hasil uji secara kualitatif sampel jamu menunjukkan 2 dari 5 sampel menunjukkan mengandung parasetamol. Kemudian hasil dari ketiga sampel ini dilanjutkan dengan pengujian kuantitatif menggunakan Spektrofotometer UVVis.

Tabel 1. Hasil analisis kualitatif parasetamol secara KLT

\begin{tabular}{cccccc}
\hline No. & $\begin{array}{c}\text { Baku dan } \\
\text { Sampel }\end{array}$ & $\begin{array}{c}\text { Tinggi } \\
\text { Bercak } \\
(\mathbf{c m})\end{array}$ & $\begin{array}{c}\text { Jarak } \\
\text { Rambat } \\
(\mathbf{c m})\end{array}$ & $\begin{array}{c}\text { Harga } \\
\text { Rf }\end{array}$ & Hasil \\
\hline 1 & Baku & 6 & 8 & 0,75 & + \\
2 & A & 7,1 & 8 & 0,89 & - \\
3 & B & 7,0 & 8 & 0,87 & - \\
4 & C & 6 & 8 & 0,75 & + \\
5 & D & 6 & 8 & 0,75 & + \\
6 & E & 4,9 & 8 & 0,6098 & - \\
\hline
\end{tabular}

Keterangan :

$\begin{array}{ll}\text { BP } & : \text { Baku pembanding } \\ \text { A,B,C,D,E } & : \text { Kode sampel }\end{array}$

Hasil uji kuantitatif yang dimana memberikan hasil pada panjang gelombang $254 \mathrm{~nm}$ dengan pembacaan larutan baku seri yang ditampilkan pada tabel 2.

Tabel 2. Hasil serapan deret larutan baku parasetamol

\begin{tabular}{ccc}
\hline No. & Konsentrasi $(\mathrm{ppm})$ & Absorbansi \\
\hline 1 & 2 & 0,002 \\
2 & 4 & 0,009 \\
3 & 6 & 0,016 \\
4 & 8 & 0,024 \\
5 & 10 & 0,032 \\
\hline
\end{tabular}

Berdasarkan hasil analisis, sampel C memiliki rata-rata serapan 0,025 dan sampel $\mathrm{D}$ memiliki rata-rata serapan 0,018 . 
Tabel 3. Hasil analisis kuantitatif sampel jamu C dan D yang mengandung Parasetamol

\begin{tabular}{ccccc}
\hline $\begin{array}{l}\text { Kode } \\
\text { sampel }\end{array}$ & $\begin{array}{c}\text { Pengukuran } \\
\text { ke- }\end{array}$ & $\begin{array}{c}\text { Serapan } \\
\text { sampel }\end{array}$ & $\begin{array}{c}\text { Rata-rata } \\
\text { serapan }\end{array}$ & $\begin{array}{c}\text { Kadar } \\
(\mathrm{mg} / \mathrm{Kg})\end{array}$ \\
\hline $\mathrm{C}$ & 1 & 0,023 & 0,025 & 8,13 \\
& 2 & 0,024 & & \\
& 3 & 0,028 & & \\
\hline $\mathrm{D}$ & 1 & 0,018 & 0,018 & 6,28 \\
& 2 & 0,019 & & \\
& 3 & 0,017 & & \\
\hline
\end{tabular}

Dari sampel jamu pegal linu yang mengandung $\mathrm{BKO}$ adalah sampel jamu dengan kode sampel $\mathrm{C}$ dan $\mathrm{D}$ yang dimana sampel $\mathrm{C}$ memiliki rata-rata serapan 0,025 dan sampel $\mathrm{D}$ memiliki rata-rata serapan 0,018 . Dari hasil ratarata ini dimasukkan ke dalam rumus persamaan regresi linier yang didapat dari pengukuran kurva kalibrasi $\mathrm{y}=0,0038 \mathrm{x}-0,0059$. Dengan didapat nilai $\mathrm{x}$ untuk sampel $\mathrm{C}=8,13 \mathrm{ppm}$ dan $\mathrm{x}$ untuk sampel $\mathrm{D}=6,28 \mathrm{ppm}$. Kedua jenis jamu ini berbentuk serbuk yang diduga memiliki khasiat menghilangkan rasa sakit dan rasa pegal. Di samping itu sediaan jamu ini juga tidak memiliki tanda registrasi dari Badan POM yang diduga kemungkinan jamu ini diproduksi dalam rumah tangga. Sehingga pengujian dan syarat-syarat dalam kualitas sediaan jamu terabaikan (Indriatmoko et al., 2019).

Parasetamol merupakan BKO yang sering disematkan ke dalam sediaan jamu pegal linu yang sebenarnya penggunaannya dilarang oleh Badan POM dalam Per-Ka BPOM No.12 tahun 2014 tentang Persyaratan Mutu Obat Tradisional bahwa serbuk dan bahan baku simplisia dilarang ditambahkan ke dalam sediaan jamu yang tidak diketahui jumlah dosis yang diberikan. Penggunaan parasetamol yang berlebihan pada jamu pegal linu dalam jangka panjang dapat menyebabkan gangguan sistem pencernaan, kerusakan fungsi hati, gangguan fungsi ginjal, serta reaksi hipersensitivitas berat Steven Johnson Syndrom (Yulisna \& Arti, 2018).

\section{Kesimpulan}

Berdasarkan hasil penelitian yang dilakukan dengan cara analisis kualitatif menggunakan KLT menunjukkan keberadaan BKO parasetamol pada jamu sampel $\mathrm{C}$ dan sampel D. Hasil penelitian dari analisis kuantitatif dengan metode
Spektrofotometer UV-Vis menunjukkan sampel C sebanyak $8,13 \mathrm{mg} / \mathrm{Kg}$ dan sampel $\mathrm{D}$ sebanyak $6,28 \mathrm{mg} / \mathrm{Kg}$.

\section{Daftar Pustaka}

BPOM. (2006). Bahaya Bahan Kimia Obat (Bko) Yang Dibubuhkan Kedalam Obat Tradisional (Jamu). Badan Pengawasan Obat Dan Makanan.

https://www.pom.go.id/new/view/more/berita /144/Bahaya-Bahan-Kimia-Obat--Bko--

Yang-Dibubuhkan-Kedalam-Obat-

Tradisional--Jamu-.html

BPOM. (2011). Peraturan Kepala Badan Pengawas Obat Dan Makanan Republik Indonesia Nomor Hk.03.1.23.06.11.5629 Tahun 2011 Tentang Persyaratan Teknis Cara Pembuatan Obat Tradisional Yang Baik. 393.

BPOM. (2015). Bahan Kimia Obat Dalam Obat Tradisional Dan Suplemen Kesehatan "Ancaman Bagi Kesehatan Masyarakat." https://www.pom.go.id/new/view/more/pers/ 285/Bahan-Kimia-Obat-Dalam-Obat-

Tradisional-Dan-Suplemen-Kesehatan---Ancaman-Bagi-Kesehatan-Masyarakat--.html

Harimurti, S., Ulandari, S., Widada, H., \& Damarwati, V. L. (2020). Identifikasi Parasetamol dan Asam Mefenamat pada Jamu Pegel Linu dan Asam Urat yang Beredar di Daerah Istimewa Yogyakarta. JPSCR: Journal of Pharmaceutical Science and Clinical Research, 5(2), 179. https://doi.org/10.20961/jpscr.v5i2.41929

Indriatmoko, D., Rudiana, T., \& Saefullah, A. (2019). Analisis Kandungan Parasetamol pada Jamu Pegal Linu yang diperoleh dari Kawasan Industri Kecamatan Kibin Kabupaten Serang. Journal Itekimia, 5(1), 33-47.

Paryono, \& Kuniarum., A. (2014). Kebiasaan Konsumsi Jamu Untuk Menjaga Kesehatan Tubuh Pada Saat Hamil Dan Setelah Melahirkan Di Desa Kajoran Klaten Selatan Paryono, Ari Kurniarum. 64-72. 
Tjahjani, N., \& Nasution, C. (2020). Gambaran Bahan Kimia Obat Parasetamol dalam Jamu Pegal Linu yang dijual di Pasar Gladak. Jurnal Farmasetis, 9(2), 89-100. http://stikeskendal.ac.id/journal/index.php/far /article/view/870

Yulisna, Y., \& Arti, N. S. (2018). Paracetamol Menyebabkan Steven Johnson Syndrome pada Wanita Berusia 24 Tahun. Jurnal Kedokteran Universitas Lampung, 2(1), 5962. 